\title{
PENGARUH ZONA KETINGGIAN TEMPAT PEMELIHARAAN TERHADAP PENAMPILAN DAN PRODUKSI KARKAS BROILER DI KABUPATEN KARANGASEM
}

\author{
AKBAR, Y. K ${ }^{1)}$, G A. M. K DEWI ${ }^{2)}$, DAN I M. NURIYASA ${ }^{2)}$ \\ 1)Program Studi Magister Ilmu Peternakan \\ 2) Fakultas Peternakan, Universitas Udayana, Denpasar \\ e-mail: arizyanuar87@gmail.com
}

\begin{abstract}
ABSTRAK
Penelitian ini bertujuan untuk mengkaji pengaruh zona ketinggian tempat pemeliharaan yang berbeda-beda terhadap penampilan dan produksi karkas broiler di Kabupaten Karangasem Provinsi Bali. Rencana penelitian yang digunakan adalah rancangan acak lengkap (RAL) yang terdiri dari tiga perlakuan dan tujuh kali ulangan. Ternak yang digunakan adalah broiler berjenis kelamin jantan berumur 14 hari sebanyak 105 ekor. Perlakuan yang diberikan adalah kandang zona ketinggian rendah o - 299 meter di atas permukaan laut (To), zona ketinggian sedang 300 - 699 meter di atas permukaan laut (T1) dan zona ketinggian tinggi >700 meter di atas permukaan laut (T2). Variabel yang diamati meliputi iklim mikro kandang, respon fisiologis, respon hematologi, penampilan dan produksi karkas. Hasil penelitian menunjukkan ketinggian tempat berpengaruh nyata $(\mathrm{P}<0,05)$ terhadap penampilan namun pada produksi karkas tidak berpengaruh nyata $(\mathrm{P}>0,05)$. Pada zona ketinggian $>700$ meter di atas permukaan laut mempengaruhi konversi ransum lebih tinggi dibandingkan dengan zona ketinggian 0 - 299 dan 300 - 699 meter di atas permukaan laut. Berdasarkan hasil penelitian ini dapat disimpulkan perlakuan To dan T1 menghasilkan penampilan lebih baik bila dibandingkan penampilan broiler pada perlakuan T2.
\end{abstract}

Kata kunci: zona ketinggian tempat, penampilan, produksi karkas. broiler

\section{EFFECT OF ALTITUDE ZONE OF A MAINTENANCE SITE ON PERFORMANCE AND BROILER CARCASS PRODUCTION IN KARANGASEM REGENCY}

\begin{abstract}
This study aims to examine the effect of zone altitude of a maintenance sites on the appearance and production of broiler tool in Karangasem regency, Bali Province. The research plan used was a Completely Randomized Design (RAL) consisting of three treatments and seven replications. Broiler male sex with 14 days age as many as 105 head were used. The treatment provided is low altitude zone 0 - 299 meters above sea level (To), medium altitude zone 300 - 699 meters above sea level (T1) and high altitude zone >700 meters above sea level (T2). Variables observed included microclimate enclosure, physiological response, haematological response, and appearance. The result showed that the height of broiler maintenance was different $(\mathrm{P}<0,05)$ to the appearance but on carcass production did not have real effect $(\mathrm{P}>0,05)$. At altitude zones $>700$ meters above sea level affect the conversion of rations higher than the height zone 0 - 299 and 300 - 699 meters above sea level. Based on this research can be concluded that treatment To and T1 produce better appearance when compared to broiler on treatment T2.
\end{abstract}

Keywords: altitude zone, appearance, production of carcass. broiler

\section{PENDAHULUAN}

Indonesia merupakan negara kepulauan dengan tiap pulau mempunyai karakteristik dataran tersendiri yang berbeda-beda yang terbagi berdasarkan ketinggian tempat, yaitu dataran rendah, sedang, dan tinggi. Perbedaan ketinggian tempat ini berpengaruh terhadap iklim mikro kandang (Qurniawan, 2016). Salah satu daerah yang memiliki keragaman ketinggian tempat berbeda adalah Kabupaten Karangasem yang terletak di Provinsi Bali, secara geografis Kabupaten Karangasem berada pada posisi $8^{\circ} 00^{\prime} 00^{\prime}$ - $8^{\circ} 41^{\prime} 37,8^{\prime \prime}$ Lintang Selatan dan $115^{\circ} 35^{\prime} 9,8^{\prime \prime}-115^{\circ} 54^{\prime} 8,9^{\prime \prime}$ Bujur Timur. Luas Kabupaten Karangasem adalah $839,54 \mathrm{Km}^{2}$ atau 
14,90\% dari luas Provinsi Bali $\left(5 \cdot 632,86 \mathrm{~km}^{2}\right)$. Bila dilihat dari penguasaan tanahnya, dari luas wilayah yang ada sekitar 7.140 ha. $(8,50 \%)$ merupakan lahan persawahan, sedangkan bukan lahan sawah 76.814 ha. (91,50\%) (Pemkab. Karangasem, 2011).

Keadaan topografi wilayah Kabupaten Karangasem beraneka ragam dan merupakan wilayah yang dinamis terdiri dari daerah dataran, perbukitan hingga daerah pegunungan, tantangan usaha peternakan broiler bila dilihat dari letak geografis kabupaten karangasem ialah memiliki iklim mikro kandang yang berbeda berdasrkan zona ketinggian tempat pemeliharaan yang berbedabeda. Ozkan et al. (2010). Menurut Qurniawan (2016) dalam penelitianya memberikan batasan dataran wilayah berdasarkan ketinggian tempat dari permukaan laut yakni sebagai berikut:

1. Dataran rendah dengan ketinggian o-299 $\mathrm{m}$ di atas permukaan laut (dpl)

2. Dataran sedang dengan ketinggian $300-699 \mathrm{~m}$ di atas permukaan laut (dpl)

3. Dataran tinggi dengan ketinggian $>700 \mathrm{~m}$ di atas permukaan laut (dpl)

Qurniawan (2016) menyatakan dalam penelitianya bahwa ayam broiler yang dipelihara selama 42 hari pada zona ketinggian $>700 \mathrm{~m}$ dpl menghasilkan pertambahan berat badan 811,25 g dan pencapaian berat badan akhir $3255 \mathrm{~g}$. Lebih baik dari ayam broiler yang dipelihara pada zona ketinggian o - $699 \mathrm{~m} \mathrm{dpl}$ menghasilkan pertambahan berat badan antara 730,80 - 777,5 g dan berat akhir antara 3032 - 3110 g. Kondisi topografi yang beragam memiliki pengaruh terhadap karakteristik iklim mikro suatu wilayah (Syamsuryadi, 2016).

Tujuan penelitian ini adalah untuk mengetahui pengaruh ketinggian tempat pemeliharaan pada ketinggian o - $299 \mathrm{~m} \mathrm{dpl}$ (rendah), 300 - $699 \mathrm{~m} \mathrm{dpl} \mathrm{(sedang)} \mathrm{dan}$ $>700 \mathrm{~m}$ dpl (tinggi) terhadap penampilan dan produksi karkas ayam broiler di Kabupaten Karangasem.

\section{MATERI DAN METODE}

\section{Rancangan Penelitian}

Penelitian ini menggunakan rancangan acak lengkap (RAL) dengan tiga perlakuan dan tujuh ulangan. Ketiga perlakuan mengacu pada penelitian Qurniawan (2016) yang membagi menjadi tiga zona ketinggian antara lain: zona ketinggian rendah o - $299 \mathrm{~m} \mathrm{dpl} \mathrm{(To),} \mathrm{zona}$ ketinggian sedang $300-690 \mathrm{~m} \mathrm{dpl}$ (T1), dan zona ketinggian tinggi $>700 \mathrm{~m} \mathrm{dpl}(\mathrm{T} 2)$.

Penelitian menggunakan broiler berjenis kelamin jantan umur 14 hari, dengan masa adaptasi 13 hari. Setelah umur 14 hari ayam dipindahkan ke kandang penelitian yang telah disiapkan. Total ayam yang digunakan sebanyak 105 ekor dengan 3 perlakukan dan
7 ulangan, setiap unit perlakuan menggunakan 5 ekor broiler.

\section{Variabel Penelitian \\ Konsumsi ransum}

Konsumsi ransum dihitung dengan cara menghitung selisih antara jumlah pemberian ransum dengan sisa pada tempat ransum, kemudian dibagi jumlah ternak.

$$
\text { pemberian ransum (g)-sisa ransum }(\mathrm{g})
$$

Konsumsi ransum $\frac{\text { pom }}{(\text { ekor } / g)}$

\section{Berat badan akhir}

Berat badan akhir ditentukan dengan menimbang bobot akhir.

\section{Pertambahan bobot badan}

Pertambahan bobot badan didapatkan dengan cara mengurangi bobot badan pada akhir penelitian dengan bobot badan pada awal penelitian.

\section{Konversi ransum}

Konversi ransum atau feed conversion ratio (FCR) dihitung dengan perbandingan antara jumlah ransum yang dikonsumsi dengan pertambahan berat badan selama penelitian (Septrialdo, 2012).

\section{Karkas}

Berat karkas adalah berat potong dikurangi dengan berat darah, bulu, kepala, kaki, serta organ dalam yang meliputi jantung, limpa, saluran pencernaan, hati dan lemak (Santoso et al., 2002)

\section{Persentase karkas}

$$
\text { Persentase karkas }=\frac{\text { Bobot karkas }}{\text { Bobot potong }} \times 100 \%
$$

\section{Potongan karkas komersial}

Potongan karkas komersial terbagi atas dada, sayap, paha dan punggung (Resnawati, 2004).

Potongan karkas komersial $=\frac{\text { Bobot recahan karkas }}{\text { Bobot karkas }} \times 100 \%$

\section{Persentase recahan karkas daging, tulang, dan lemak}

Persentase daging, diperoleh dengan membagi bobot daging pada dada,sayap, dan paha dengan berat karkas dikali 100\%.

$$
\text { Persentase daging }=\frac{\text { Bobot daging }}{\text { Bobot karkas }} \times 100 \%
$$


Persentase tulang, diperoleh dengan membagi bobot tulang pada dada,sayap, dan paha dengan berat karkas dikali $100 \%$.

$$
\text { Persentase tulang }=\frac{\text { Bobot tulang }}{\text { Bobot karkas }} \times 100 \%
$$

Persentase kulit dan lemak, diperoleh dengan membagi bobot lemak pada dada,sayap, dan paha dengan berat karkas dikali 100\%.

\section{Analisa Data}

Data yang diperoleh dianalis ragam, apabila diantara perlakuan terdapat perbedaan yang nyata $(\mathrm{P}<0.05)$, maka dilanjutkan dengan Uji Jarak Berganda Duncan dengan tingkat signifikan 5\% (Steel dan Torrie,1991).

\section{HASIL DAN PEMBAHASAN}

Broiler yang dipelihara pada kandang pada zona ketingggian 0-299 $\mathrm{m} \mathrm{dpl}$ atau To menunjukkan penampilan lebih baik dari segi konversi ransum lebih rendah $(\mathrm{P}<0,05)$ daripada broiler pada kandang $\mathrm{T} 1$ dan T2 yakni sebesar 10,24\% dan 6,10\%. Sedangkan variabel penampilan pertambahan berat badan, konsumsi ransum dan berat badan akhir menunjukan pengaruh yang tidak berbeda nyata $(\mathrm{P}>0,05)$ antara perlakuan $\mathrm{T} 2$ dibandingkan dengan To dan $\mathrm{T} 1$.

Tabel 1. Pengaruh zona ketinggian tempat terhadap penampilan dan karkas broiler

\begin{tabular}{lcccc}
\hline \multirow{2}{*}{\multicolumn{1}{c}{ Variabel }} & \multicolumn{3}{c}{ Perlakuan } & \multirow{2}{*}{ SEM } \\
\cline { 2 - 4 } & T0 & T1 & T2 \\
\hline Penampilan: & & & & \\
Berat badan awal (g/ekor) & $462^{\mathrm{a}}$ & $462^{\mathrm{a}}$ & $470^{\mathrm{a}}$ & 4,189 \\
BB Akhir (g/ekor) & $1762^{\mathrm{a}}$ & $1676^{\mathrm{a}}$ & $1671^{\mathrm{a}}$ & 31,823 \\
PBB (g/ekor) & $1300^{\mathrm{a}}$ & $1214^{\mathrm{a}}$ & $1201^{\mathrm{a}}$ & 28,615 \\
Konsumsi ransum (g/ekor) & $1913^{\mathrm{a}}$ & $1870^{\mathrm{a}}$ & $1970^{\mathrm{a}}$ & 27,314 \\
Konversi ransum & $1,472^{\mathrm{b}}$ & $1,540^{\mathrm{b}}$ & $1,640^{\mathrm{a}}$ & 0,028 \\
Karkas: & & & & \\
Berat potong (g) & $1754^{\mathrm{a}}$ & $1739^{\mathrm{a}}$ & $1748^{\mathrm{a}}$ & 29,712 \\
Karkas (\% berat potong) & $73,103^{\mathrm{a}}$ & $69,991^{\mathrm{a}}$ & $71,344^{\mathrm{a}}$ & 11,022 \\
Dada + punggung (\% karkas) & $48,183^{\mathrm{a}}$ & $48,945^{\mathrm{a}}$ & $49,897^{\mathrm{a}}$ & 0,897 \\
Paha (\% karkas) & $40,847^{\mathrm{a}}$ & $40,983^{\mathrm{a}}$ & $39,345^{\mathrm{a}}$ & 0,497 \\
Sayap (\% karkas) & $10,955^{\mathrm{a}}$ & $9,882^{\mathrm{a}}$ & $10,708^{\mathrm{a}}$ & 0,663 \\
Daging (\% karkas) & $54,681^{\mathrm{a}}$ & $55,961^{\mathrm{a}}$ & $54,071^{\mathrm{a}}$ & 1,711 \\
Tulang (\% karkas) & $32,074^{\mathrm{a}}$ & $31,125^{\mathrm{a}}$ & $33,208^{\mathrm{a}}$ & 1,832 \\
Kulit + Lemak (\% karkas) & $13,264^{\mathrm{a}}$ & $12,725^{\mathrm{a}}$ & $12,721^{\mathrm{a}}$ & 0,568 \\
\hline
\end{tabular}

Temperatur kandang pada zona ketinggian $>700$ $\mathrm{m}$ dpl (T2) mencapai $23,20^{\circ} \mathrm{C}$ pada suhu ini ayam mengalami cekaman dingin (hipotermia) untuk mempertahankan suhu tubuh agar tetap pada suhu tubuh normal broiler perlu mengkonsumsi pakan lebih banyak untuk memenuhi kebutuhan energi yang berbeda dengan dataran yang lebih rendah, hal ini sependapat dengan pernyataan Kusnadi (2006), ayam pedaging termasuk hewan homeothermis dengan suhu nyaman $24,0^{\circ} \mathrm{C}$ yang akan berusaha mempertahankan suhu tubuhnya antara lain konsumsi pakan lebih tinggi, kebutuhan konsumsi pakan pada perlakuan T2 banyak dipergunakan unutk mempertahankan suhu tubuh agar tetap konstan pada $40,5-41,5^{\circ} \mathrm{C}$ (Etches et al., 2008) sehingga adanya persaingan antara kebutuhan nutrisi untuk pertumbuhan dan kebutuhan energi untuk mempertahankan suhu tubuh. Hal ini yang menyebabkan konversi ransum pada perlakuan T2 lebih tinggi dari pada perlakuan To dan T1.

Hasil penelitian variabel persentase karkas menunjukkan hasil berbeda tidak nyata $(\mathrm{P}>0,05)$ antara perlakuan To, T1 dan T2 baik yang meliputi Persentase karkas, dada + punggung, paha, Sayap, daging, tulang, kulit + lemak. Dengan kata lain zona ketinggian tempat pemeliharaan tidak berpengaruh nyata terhadap variabel karkas. Tidak berbeda nyata hasil pengamatan persentase karkas komersial dan Non komersial antara perlakuan To, T1 dan T2 dipengaruhi oleh persentase karkas yang tidak berbeda nyata antara perlakuan To, T1 dan T2. Tingginya persentase karkas yang dihasilkan akan mempengaruhi nilai recahan karkas komersial dan non komersial karkas, sebaliknya rendahnya persentase karkas akan mempengaruhi rendahnya nilai recahan karkas komersial dan non komersial. Hasil penelitian ini menunjukan dengan berat potong yang tidak berbeda nyata akan menghasilkan persentase karkas dan nilai recahan karkas yang sama, hasil ini didukung oleh pernyataan Haroen (2003) yang menyatakan rataan persentase karkas broiler dipengaruhi oleh berat akhir broiler.

\section{SIMPULAN}

Dari hasil penelitian ini maka dapat disimpulkan sebagai berikut: (1) Zona ketinggian tempat pemeliharaan mampu mempengaruhi penampilan ayam broiler namun tidak berpengaruh terhadap produksi karkas ayam broiler. (2) Pemeliharaan ayam broiler pada zona ketinggian ketinggian o - $299 \mathrm{~m} \mathrm{dpl}$ (To) dan 300 - $699 \mathrm{~m}$ dpl (T1) menunjukan konversi ransum lebih rendah dibandingkan broiler yang dipelihara pada zona ketinggian $>700 \mathrm{~m} \mathrm{dpl} \mathrm{(T2).}$

\section{UCAPAN TERIMAKASIH}

Penulis mengucapkan terimakasih kepada Ibu Prof. Dr. Ir. G.A.M. Kristina Dewi. MS dan Bapak Dr. Ir. I Made Nuriyasa, MS yang telah membantu penulis dari awal penulisan sampai akhir penulisan. 


\section{DAFTAR PUSTAKA}

Etches, R.J., T.M. John, and A.M. Verrinder Gibbins. 2008. Behavioural, physiological, neuroendocrine and molecular responses to heat stress. In: Daghir NJ, editor. Poult Prod hot Clim. p. 49-69.

Haroen. U. 2003. Respon ayam broiler yang diberi tepung daun sengon (Albizzia falcataria) dalam ransum terhadap pertumbuhan dan hasil karkas. J. Ilmiah Ilmu-ilmu Peternakan. 6 (1):34-41.

Kusnadi, E., R. Widjajakusuma, T. Sutardi, P. S. Hardjosworo, dan A. Habibie. 2006. Pemberian antanan (Cantella asiatica) dan vitamin C sebagai upaya mengatasi efek cekaman panas pada broiler. Media Peternakan 29(3): 133-140.

Ozkan S, C. Takma, S. Yahav, B. Sogut, L. Turkmut, H. Erturun, A. Cahaner. 2010. The effects of feed restriction and ambient temperature on growth and ascites mortality of broilers reared at high altitude. Poultry Science. 89:974-985.
Pemerintah Kabupaten Karangasem. 2011. Pokja Sanitasi 2011. http://karangasemkab.go.id [20 juni 2017].

Qurniawan, A. 2016. Peformans Produksi Ayam Pedaging pada Lingkungan Pemeliharaan dengan Ketinggian yang Berbeda di Sulawesi Selatan. Tesis. Institut Pertanian Bogor. Bogor.

Santoso, S. 2002 Statistik Parametrik, Cetakan Ketiga, PT Gramedia Pustaka. Utama, Jakarta.

Septrialdo, S. 2012. Pengaruh Suhu Terhadap Produksi Dan Tingkat Kematian (Mortalitas) Broiler Di Kabupaten Lima Puluh Kota. Universitas andalas. Padang.

Steel, R.G.D. and J.H. Torrie. 1991. Principle and Procedures of Statistics. 2th. Ed. Mc Graw Hill International Book Company. London.

Syamsuryadi, B. 2016. Produktivitas Ayam Pedaging pada Ketinggian Tempat Pemeliharaan Berbeda di Provinsi Sulawesi Selatan. Tesis. Institut pertanian bbgor. Bogor. 